Article

\title{
Exercise-Induced Oxygen Desaturation during the 6-Minute Walk Test
}

\author{
Raghav Gupta ${ }^{1,2, *}$, Gregg L. Ruppel ${ }^{3}$ and Joseph Roland D. Espiritu ${ }^{3}$ \\ 1 Department of Pulmonary and Critical Care Medicine, Deaconess Health System, Evansville, IN 47747, USA \\ 2 Indiana University School of Medicine, Evansville, IN 47710, USA \\ 3 Division of Pulmonary, Critical Care, and Sleep Medicine, Saint Louis University School of Medicine, \\ Saint Louis, MO 63103, USA; ruppelgl@slu.edu (G.L.R.); joseph.espiritu@health.slu.edu (J.R.D.E.) \\ * Correspondence: drraghav11@gmail.com
}

Received: 15 November 2019; Accepted: 21 January 2020; Published: 31 January 2020

check for updates

\begin{abstract}
The 6-minute walk test (6MWT) is not intended to document oxygen $\left(\mathrm{O}_{2}\right)$ desaturation during exertion but is often used for this purpose. Because of this, it only has modest reproducibility in determining the need for ambulatory $\mathrm{O}_{2}$ therapy in patients with cardiopulmonary disease. The diagnostic and prognostic value of detecting exertional $\mathrm{O}_{2}$ desaturation is still unknown. The aims of this study were to estimate the prevalence of $\mathrm{O}_{2}$ desaturation during a $6 \mathrm{MWT}$ based on pulse oximetry measurements at the beginning and end of a $6 \mathrm{MWT}$ in a clinical population of patients with suspected cardiopulmonary disease and to determine whether the pulmonary function test (PFT) can predict exercise-induced desaturation during a 6MWT. This retrospective cohort study reviewed the results of the 6MWT and the PFT (i.e., spirometry, lung volumes, and diffusion capacity) of all patients who were evaluated for suspected cardiopulmonary disease at an academic medical center during a 5-year study period. The patients were categorized into three groups based on the change in $\mathrm{O}_{2}$ saturation by pulse oximetry $\left(\mathrm{SpO}_{2}\right)$ from start to end of the $6 \mathrm{MWT}$ : (1) $\mathrm{SpO}_{2}$ decreased by $\geq 3 \%$; (2) $\mathrm{SpO}_{2}$ unchanged ( $-2 \leq \Delta \leq 0 \%$ ); and (3) $\mathrm{SpO}_{2}$ increased by $\geq 1 \%$. Demographic, anthropometric, and lung function measurements were analyzed to determine which factors predicted $\mathrm{O}_{2}$ desaturation during the 6MWT. Of the 319 patients who underwent the 6MWT and the PFT from November 2005 until December 2010 (mean age $=54 \pm 0.78$ years, 63\% women, 58\% Whites, body mass index $\left.=29.63 \pm 8.10 \mathrm{~kg} / \mathrm{m}^{2}\right), 113(35 \%)$ had a decreased $\mathrm{SpO}_{2}, 146(46 \%)$ had no change, and $60(19 \%)$ had an increased $\mathrm{SpO}_{2}$ from the start to end of test. Our bivariate analysis found age, spirometric measures, and diffusion capacity for carbon monoxide (DLCO) had statistically significant inverse associations with the $\mathrm{SpO}_{2}$ change category $(p<0.001)$. Both a 3\% and $4 \%$ drop in $\mathrm{SpO}_{2}$ during the $6 \mathrm{MWT}$ were statistically significantly associated with an older age, a higher prevalence of obstruction, and reduced forced vital capacity (FVC), forced expiratory volume in one second $\left(\mathrm{FEV}_{1}\right), \mathrm{FEV}_{1} / \mathrm{FVC}$, DLCO and 6-minute walk distance (6MWD). Multivariable logistic regression analyses revealed that only DLCO was a significant independent predictor of the change in $\mathrm{SpO}_{2}$ and a $\geq 4 \% \mathrm{O}_{2}$ desaturation during a 6MWT. Receiver operating curve analysis indicates DLCO cut-off of $45 \%$ is $82 \%$ sensitive and $40 \%$ specific in identifying $\geq 4 \% \mathrm{O}_{2}$ desaturators, with an area under the curve of $0.788 \pm 0.039(p<0.001)$. The prevalence of $\mathrm{a} \geq 3 \%$ oxygen desaturation via pulse oximetry during a $6 \mathrm{MWT}$ in our clinical population of patients with suspected cardiopulmonary disease was $35 \%$. Although age, spirometric lung volumes, and DLCO had statistically significant unadjusted inverse associations with the change in $\mathrm{SpO}_{2}$ during a $6 \mathrm{MWT}$, the DLCO is the only significant independent predictor of both the magnitude of the change in $\mathrm{SpO}_{2}$ and the occurrence of $\mathrm{O}_{2}$ desaturation of at least $4 \%$, respectively, during the test. Clinical Implications: A DLCO cut-off of $45 \%$ may be useful in identifying patients at risk for exertional hypoxemia during a 6MWT.
\end{abstract}

Keywords: six-minute walk test; oxygen desaturation; predictors 


\section{Introduction}

Functional exercise capacity is an important measure for evaluating and monitoring patients with cardiopulmonary disease. Various modalities have been used to measure exercise capacity including a 6-minute walk test (6MWT), stair climbing, a shuttle-walk test, and a cardiac pulmonary exercise testing (CPET) [1]. The 6MWT has been broadly used in clinical settings for its patient tolerability, ease of implementation without need for special equipment and good correlation with patient outcomes [2,3]. It provides information regarding functional capacity, response to therapy and prognosis across a range of chronic cardiopulmonary conditions [4]. The 6MWT yields three main measurements: 6-minute walk distance (6MWD), exercise-induced oxygen desaturation (EID), defined as an oxygen saturation by pulse oximetry $\left(\mathrm{SpO}_{2}\right)$ to $\leq 88 \%$, and self-perceived dyspnea as assessed by the Borg scale [5]. It is well known that the 6MWD is a predictor of mortality, primarily in patients with cardiopulmonary disease [6]. In addition, patients who developed oxygen $\left(\mathrm{O}_{2}\right)$ desaturation during the 6MWT had a higher mortality rate than patients who did not $(67$ vs. $38 \%, p<0.001)$ [7].

The 6MWD has been known to correlate well with pulmonary function test (PFT) variables including forced expiratory volume in one second $\left(\mathrm{FEV}_{1}\right)$, forced vital capacity (FVC) and diffusion capacity for carbon monoxide (DLCO) [8]. Chen et al. found $\mathrm{FEV}_{1}$ to be a predictor of $6 \mathrm{MWD}$ in stable chronic obstructive pulmonary disease but was not associated with either $\mathrm{O}_{2}$ desaturation or dyspnea measured on the BORG scale [9]. The FVC and DLCO were found to be strongly correlated with 6MWD in idiopathic pulmonary fibrosis (IPF) patients [10]. A DLCO $<50 \%$ of predicted and an FVC $<80 \%$ of predicted were the best parameters to identify abnormal $6 \mathrm{MWD}$ in patients with scleroderma-associated interstitial lung disease (ILD) [11]. Although PFT variables appear to correlate well with the 6MWD, less is known about the prediction of $\mathrm{O}_{2}$ desaturation [12].

Poulain et al. demonstrated the reproducibility of EID during the 6MWT patients with lung disease when compared to CPET [13]. Guyatt and colleagues also found that measuring $\mathrm{O}_{2}$ saturation by pulse oximetry $\left(\mathrm{SpO}_{2}\right)$ during a 6MWT could establish a baseline value for ascertaining improvements in $\mathrm{SpO}_{2}$ during repeated testing [14]. The American Thoracic Society (ATS) 2002 6MWT guidelines made a clear statement of not measuring $\mathrm{O}_{2}$ continuously throughout the test due to motion artifact $[4,15]$. After 2002, multiple studies have shown the reliability of measuring $\mathrm{SpO}_{2}$ during a 6MWT [16,17]. An updated statement from European Respiratory Society (ERS) and ATS now recommends using $6 \mathrm{MWT}$ as a standard $\mathrm{O}_{2}$ desaturation test with the use of a pulse oximeter for continuous measurement of the $\mathrm{SpO}_{2}$ and heart rate (HR) $[8,18]$.

Previous studies have observed $\mathrm{O}_{2}$ desaturation to occur commonly during the 6MWT [19-21]. Paciocco et reported that 18 of 34 (53\%) of pulmonary hypertensive patients experienced a $\geq 10 \% \mathrm{O}_{2}$ desaturation during the $6 \mathrm{MWT}$ and an almost 3-fold increased mortality over a 5 year follow up. ${ }^{19}$ Jenkins et al. reported a $47 \%$ prevalence of significant $\mathrm{O}_{2}$ desaturation defined as a $\geq 4 \%$ fall in $\mathrm{SpO}_{2}$ to $<90 \%$ in a large cohort of patients with chronic lung disease, with pre-exercise $\mathrm{SpO}_{2}$ and forced expiratory volume in $1 \mathrm{~s}\left(\mathrm{FEV}_{1}\right)$ as significant predictors of desaturation [20]. An analysis of the 6MWT in cystic fibrosis patients with mild-to-moderate lung disease by Chetta et al. identified forced expiratory volume in $1 \mathrm{~s}\left(\mathrm{FEV}_{1}\right)$ as the only independent predictor of $\mathrm{SpO}_{2}$ during a 6MWT [21]. Knowledge of which PFT measurements predict $\mathrm{O}_{2}$ desaturation during exercise can assist the clinician in identifying patients who may require $\mathrm{O}_{2}$ supplementation during exercise, in order to relieve exertional dyspnea and enhance exercise capacity. Thus, the aims of this study were to estimate the prevalence of $\mathrm{O}_{2}$ desaturation during a $6 \mathrm{MWT}$ based on $\mathrm{SpO}_{2}$ measurements from the beginning and end of the $6 \mathrm{MWT}$ in a clinical population of patients with suspected cardiopulmonary disease and to determine whether the PFT can predict EID during a 6MWT. 


\section{Materials and Methods}

\subsection{Patient Selection}

This retrospective cohort study evaluated all adult patients who underwent the PFT and the 6MWT for various clinical indications (e.g., cardiopulmonary disorders) from November 2005 until December 2010. The only exclusion criterion was the absence of either PFT or 6MWT results. The patients were initially categorized into 3 groups based on the magnitude of the change in $\mathrm{SpO}_{2}$ from the start to the end of the $6 \mathrm{MWT}\left(\Delta=\mathrm{SpO}_{2}\right.$ at end of test-SpO $\mathrm{Sp}_{2}$ at start of test): (1) $\mathrm{SpO}_{2}$ increased $(\Delta \geq+1 \%)$; (2) $\mathrm{SpO}_{2}$ unchanged $(-2 \leq \Delta \leq 0 \%)$; and (3) $\mathrm{SpO}_{2}$ decreased $(\Delta \leq-3 \%)$. Since the existing literature was unclear as to the range of normal change $(\Delta)$ in $\mathrm{SpO}_{2}$ during a $6 \mathrm{MWT}$, we selected an arbitrary cut-off of $\leq-3 \%$ to define the "SpO $\mathrm{Sp}_{2}$ decreased" group which experienced clinically significant decrements in $\mathrm{SpO}_{2}$ during the test. The rationale for the $-3 \%$ cut-off is that most pulse oximeter manufacturers claim an accuracy of $2 \%$, which is the standard deviation of the differences between the $\mathrm{SpO}_{2}$ by pulse oximetry and the $\mathrm{SaO}_{2}$ by CO-oximetry [22]. Assuming that moderate exercise during a 6MWT should not result in any significant change in oxygenation in normal individuals, patients whose $\mathrm{SpO}_{2}$ changes were minimal ( -2 to $0 \%$ ) where categorized under the "SpO $\mathrm{P}_{2}$ unchanged" group. We assigned an arbitrary cut-off of $\geq+1 \%$ to categorize those patients whose $\mathrm{SpO}_{2}$ increased during moderate exercise with the purpose of identifying patients whose ventilation-perfusion matching might improve with the increase in tidal volume, heart rate, and stroke volume associate with moderate exercise. We also binarily categorized the patients as "oxygen desaturators" vs. "non-desaturators" based on whether the patient had an $\mathrm{SpO}_{2}$ drop of at least $4 \%$ during the $6 \mathrm{MWT}$.

\subsection{Measurements}

\section{Demographic and Anthrompometric Variables}

Demographic data (i.e., age, sex, and race) and anthropometric measurements (i.e., height, weight, body mass index or BMI) at the time of the PFT were retrospectively collected from the PFT technical report and/or 6MWT.

\subsection{Pulmonary Function Test Protocol}

The PFT was conducted following the recommendations of the ATS and ERS Task Force on the standardization of spirometry and measurement of lung volumes and their technical statement on the measurement of the single-breath carbon monoxide uptake in the lung, respectively. Pre-bronchodilator forced vital capacity (FVC), forced expiratory volume in $1 \mathrm{~s}\left(\mathrm{FEV}_{1}\right), \mathrm{FEV}_{1} / \mathrm{FVC}$ ratio, total lung capacity (TLC), residual volume (RV), and diffusion capacity for carbon monoxide (DLCO) were collected in our data file. The DLCO value was adjusted for hemoglobin by applying Cotes' equation:

$$
\text { adjusted DLCO }=[\text { DLCO } \times(10.2+\text { hemoglobin }) /(1.7 \times \text { hemoglobin })]
$$

We categorized patient's PFT results as "obstruction" if the FEV 1 /FVC ratio is less than 0.70; "restriction" if the total lung capacity is less $80 \%$ of predicted; and "combined obstruction and restriction" if both are present.

\subsection{The 6-Minute Walk Test Protocol}

The 6MWT was performed in accordance with ATS guidelines published in March 2002. The 6-minute walk distance (6MWD) and the $\mathrm{SpO}_{2}$, Borg dyspnea score, Fatigue score, and pulse rate at the start and end of the test were collected in the data file. Pulse oximetry $\mathrm{SpO}_{2} \mathrm{was}_{\text {measured via a }}$ finger probe using a Masimo Rad 5 with Adult Sensor (Masimo, Irvine, CA, USA) while standing at the beginning of the 6MWT and then again while standing at the end of the test after 6-min of walking. For patients who had never been prescribed $\mathrm{O}_{2}$ supplementation, pulse oximetry was conducted on room 
air. For patients who had previously required $\mathrm{O}_{2}$ supplementation, pulse oximetry was performed on their prescribed $\mathrm{O}_{2}$ flow rate via nasal cannula or fraction of inspired $\mathrm{O}_{2}\left(\mathrm{~F}_{\mathrm{i}} \mathrm{O}_{2}\right)$ via mask.

\subsection{Statistical Analysis}

We calculated the prevalence of EID, defined as a drop of at least 3 or $4 \%$ in $\mathrm{SpO}_{2}$ from the start to the end of the 6MWT. Analysis of variance (ANOVA) and $\chi^{2}$ tests were employed to determine whether demographic (i.e., age, sex, and race) and anthropometric (i.e., height, weight, and BMI) characteristics, PFT variables (i.e., pre-bronchodilator FVC, FEV 1 , FEV 1 FVC; TLC, RV, DLCO, and airway resistance), lung function abnormalities (i.e., "obstruction", "restriction", or "combined obstruction and restriction"), and $6 \mathrm{MWD}$ were associated with the (1) category of $\mathrm{SpO}_{2}$ change (i.e., increased, unchanged, or decreased) and (2) a $\geq 4 \% \mathrm{O}_{2}$ desaturation ( $\geq 4 \%$ Desaturators vs. Nondesaturators), respectively. Repeated Measures ANOVA was also conducted to determine whether the change in 6MWT measures (i.e., $\mathrm{SpO}_{2}$, Borg Dyspnea and Fatigue Scale scores, and pulse rate) from the start to the end of the test were statistically different among categories of $\mathrm{SpO}_{2}$ change (i.e., increased, unchanged or decreased) and between $\geq 4 \%$ Desaturators and Nondesaturators, respectively. Multivariable linear regression analysis was conducted to determine which of the significant independent demographic, anthropometric, and PFT variables were independently associated with the magnitude of the $\mathrm{SpO}_{2}$ change $(\Delta)$. We also fitted multivariable binary logistic regression models to determine whether the significant independent demographic, anthropometric, and PFT variables predicted the occurrence of a $\geq 3$ and $4 \%$ desaturation, respectively, (in order to distinguish desaturators vs. non-desaturators) during a 6MWT. Statistical analyses were performed using SPSS software (IBM SPSS Statistics for Windows, Version 22.0. Armonk, NY, USA: IBM Corp. Released 2013).

\section{Results}

\subsection{Demographic, and BMI Characteristics of Patients Based on Category of $\mathrm{SpO}_{2}$ Change during the $6 \mathrm{MWT}$}

Of the 319 patients who underwent the PFT and the 6MWT for suspected cardiopulmonary disease at our academic medical center from November 2005 until December 2010, there were 206 women $(63 \%)$ and 122 men (37\%). The racial distribution of our study participants reflected our Midwestern urban location of our academic center, with 184 (57\%) Whites, 129 (41\%) African-Americans, three (1\%) other races, and three (1\%) unknown race. The mean \pm standard deviation (SD) age was $54 \pm 0.78$ years and the mean BMI was $29.63 \pm 8.10 \mathrm{~kg} / \mathrm{m}^{2}$. Table 1 compares the demographic, clinical, and pulmonary function findings based on the category of $\mathrm{SpO}_{2} \Delta$ during a 6MWT. Of the 319 study patients, 113 (35\%) experienced an $\mathrm{SpO}_{2}$ decrease of at least 3\% from the start to the end of the 6MWT. In contrast, $146(46 \%)$ had a minimal-to-no change $\left(\mathrm{SpO}_{2} \Delta=0\right.$ to $\left.-2 \%\right)$, while 60 (19\%) achieved an increase of at least $+1 \%$. Age had a statistically significant inverse relationship with $\mathrm{SpO}_{2} \Delta$ category, with the groups whose $\mathrm{SpO}_{2}$ decreased (57.68 \pm 13.91 years) or remain unchanged ( $54.41 \pm 13.35$ years) being older than those whose $\mathrm{SpO}_{2}$ increased (48.30 \pm 13.96 years, $p \leq 0.01$ on post-hoc comparisons). There were no statistically significant differences in the sex and race distribution and BMI among the three $\mathrm{SpO}_{2}$ change categories $(p>0.05)$. 
Table 1. Demographic, clinical, and pulmonary function variables based on the change in $\mathrm{SpO}_{2}$ category during the 6-minute walk test.

\begin{tabular}{|c|c|c|c|c|}
\hline \multirow[b]{2}{*}{ Variable } & \multicolumn{3}{|c|}{$\begin{array}{c}\text { Change in } \mathrm{SpO}_{2} \\
\left(\Delta=\mathrm{SpO}_{2} \text { at End of Study-SpO } \mathrm{SpO}_{2} \text { at Start of Study) }\right.\end{array}$} & \multirow[b]{2}{*}{$p$-Value } \\
\hline & $\begin{array}{c}\text { Increased } \\
(\Delta \geq+1 \%) \\
N=60(19 \%)\end{array}$ & $\begin{array}{c}\text { Unchanged } \\
(-2 \leq \Delta \leq 0 \%) \\
N=146(46 \%)\end{array}$ & $\begin{array}{c}\text { Decreased } \\
(\Delta \leq-3 \%) \\
N=113(35 \%)\end{array}$ & \\
\hline Age, years & $48.30 \pm 13.96$ & $54.41 \pm 13.35$ & $57.68 \pm 13.91$ & $<0.001$ \\
\hline $\begin{array}{l}\text { Sex, no. }(\%) \\
\text { Male } \\
\text { Female }\end{array}$ & $\begin{array}{l}22(18) \\
37(19)\end{array}$ & $\begin{array}{l}51(42) \\
95(48)\end{array}$ & $\begin{array}{l}47(39) \\
67(33)\end{array}$ & 0.236 \\
\hline $\begin{array}{c}\text { Race, no. (\%) } \\
\text { White } \\
\text { Black } \\
\text { Hispanic } \\
\text { Asian } \\
\text { Other }\end{array}$ & $\begin{array}{c}35(19) \\
25(19) \\
0(0) \\
1(100) \\
0(0)\end{array}$ & $\begin{array}{c}84(45) \\
59(46) \\
1(100) \\
0(0) \\
0(0)\end{array}$ & $\begin{array}{c}66(36) \\
47(36) \\
0(0) \\
0(0) \\
1(100)\end{array}$ & 0.364 \\
\hline BMI $\left(\mathrm{kg} / \mathrm{m}^{2}\right)$ & $27.82 \pm 7.68$ & $30.06 \pm 8.28$ & $30.06 \pm 8.06$ & 0.157 \\
\hline Obstruction $\left(\mathrm{FEV}_{1} / \mathrm{FVC}<70 \%\right)$, no. (\%) & $12(20)$ & $35(24)$ & $46(41)$ & $<0.001$ \\
\hline Restriction (TLC < 80\%), no. (\%) & $20(33)$ & $37(25)$ & $39(35)$ & 0.114 \\
\hline Combined obstruction and restriction, no. (\%) & $0(0)$ & $2(1)$ & $3(3)$ & 0.387 \\
\hline FVC, L & $2.92 \pm 1.06$ & $2.88 \pm 0.97$ & $2.46 \pm 1.02$ & 0.003 \\
\hline FVC, \%predicted & $76.33 \pm 16.71$ & $79.85 \pm 16.53$ & $68.56 \pm 23.24$ & $<0.001$ \\
\hline $\mathrm{FEV}_{1} \mathrm{~L}$ & $2.16 \pm 0.93$ & $2.10 \pm 0.76$ & $1.63 \pm 0.77$ & $<0.001$ \\
\hline $\mathrm{FEV}_{1}, \%$ predicted & $70.91 \pm 23.49$ & $74.85 \pm 20.23$ & $58.12 \pm 21.89$ & $<0.001$ \\
\hline $\mathrm{FEV}_{1} / \mathrm{FVC}$ ratio & $73.15 \pm 16.99$ & $73.86 \pm 14.56$ & $67.31 \pm 21.21$ & 0.014 \\
\hline TLC, L & $4.91 \pm 1.41$ & $4.92 \pm 1.47$ & $4.67 \pm 1.55$ & 0.418 \\
\hline TLC, \%predicted & $89.12 \pm 18.31$ & $91.67 \pm 21.52$ & $85.92 \pm 26.71$ & 0.174 \\
\hline $\mathrm{RV}, \mathrm{L}$ & $2.01 \pm 0.94$ & $2.08 \pm 1.01$ & $2.23 \pm 1.10$ & 0.363 \\
\hline RV, \%predicted & $114.82 \pm 53.17$ & $113.01 \pm 49.08$ & $117.41 \pm 58.12$ & 0.825 \\
\hline $\mathrm{DLCO}, \mathrm{mL} / \mathrm{min} / \mathrm{mmHg}$ & $14.85 \pm 5.36$ & $15.58 \pm 6.15$ & $10.59 \pm 0.94$ & $<0.001$ \\
\hline DLCO, \%predicted & $64.57 \pm 21.55$ & $71.40 \pm 26.28$ & $45.07 \pm 19.25$ & $<0.001$ \\
\hline Airway resistance, $\mathrm{cmH}_{2} \mathrm{O} / \mathrm{L} / \mathrm{sec}$ & $1.93 \pm 1.35$ & $1.88 \pm 1.20$ & $2.27 \pm 1.48$ & 0.075 \\
\hline
\end{tabular}

$\mathrm{SpO}_{2}$ : Saturation by pulse oximetry; BMI: body mass index; FEV1: forced expiratory volume in one second; FVC: forced vital capacity; TLC: total lung capacity; RV: residual volume; DLCO: difussion capacity for carbon monoxide.

\subsection{Pulmonary Function of Patients Based on Category of $\mathrm{SpO}_{2}$ Change during the $6 \mathrm{MWT}$}

Spirometric lung volumes were also significantly associated with the $\mathrm{SpO}_{2} \Delta$ category, and the group whose $\mathrm{SpO}_{2}$ decreased by at least $3 \%$ had lower FVC $(p<0.001), \mathrm{FEV}_{1}(p<0.001)$, and $\mathrm{FEV}_{1} / \mathrm{FVC}$ ratios $(p<0.014)$ compared to the groups whose $\mathrm{SpO}_{2}$ were unchanged or increased, respectively. On the other hand, there were no statically significant differences in lung volumes (i.e., TLC and RV) or airway resistance by body plethysmography $(p>0.05)$ among the three groups. The group whose $\mathrm{SpO}_{2}$ decreased by at least 3\% also had a statistically significantly lower DLCO than the groups whose $\mathrm{SpO}_{2}$ was unchanged $(p<0.001)$ or increased $(p=0.001)$, respectively. The prevalence of obstruction based on an $\mathrm{FEV}_{1} / \mathrm{FVC}$ ratio $<0.70$ was also significantly higher in the $\mathrm{SpO}_{2}$ decreased group ( $46 \%$ ) than the $\mathrm{SpO}_{2}$ unchanged $(26 \%)$ and increased $(22 \%)$ groups, respectively $(p<0.001)$. There was no significant difference in the prevalence of restriction (TLC $<80 \%$ ) or combined obstruction and restriction among the categories of $\mathrm{SpO}_{2}$ change $(p>0.05)$. 


\subsection{The 6-Minute Walk Test Results of Patients Based on Category of $\mathrm{SpO}_{2}$ Change during the 6MWT}

Table 2 lists the results of the 6MWT for the three groups of patients categorized based on the change in $\mathrm{SpO}_{2}$ (increased, unchanged, or decreased) from the start to the end of the test. ANOVA revealed statistically significant differences in the $\mathrm{SpO}_{2}$, both at baseline and at the end of the test, among the three categories of $\mathrm{SpO}_{2}$ change. Although the baseline $\mathrm{SpO}_{2}$ values were statistically different among the three categories of $\mathrm{SpO}_{2}$ change, these differences were not clinically meaningful (increased group: $96.57 \pm 2.04 \%$, unchanged group: $97.99 \pm 1.89 \%$, and decreased group: $97.20 \pm 2.43 \%$ ) On the other hand, the $\mathrm{SpO}_{2}$ at the end of the test was both statistically and clinically significantly lower $(p<0.001)$ in the group that had at least a $-3 \%$ decrease in $\mathrm{SpO}_{2}(90.42 \pm 5.11 \%)$ compared to the increased group $(98.45 \pm 1.63 \%)$ and the unchanged group $(97.10 \pm 2.10 \%)$, respectively. Repeated Measures ANOVA found a statistically significant association between the change in $\mathrm{SpO}_{2}$ from the start to the end of the 6MWT and the three categories of $\mathrm{SpO}_{2}$ change. The group that had an increase in $\mathrm{O}_{2}$ saturation by at least $1 \%$ from start to end of the $6 \mathrm{MWT}\left(\mathrm{SpO}_{2} \Delta \geq 1 \%\right)$ had an average $+1.88 \%$ rise; the unchanged group, whose oxygen saturation dropped anywhere from 0 to $-2 \%$ from baseline $(-2 \leq \Delta \leq 0 \%)$, had a mean $-0.89 \%$ drop; and the group that had at least a $-3 \%$ drop from baseline $(\Delta \leq-3 \%)$ had a mean $-6.78 \%$ drop in $\mathrm{SpO}_{2}$ from the start to the end of the test $(p<0.001)$. In addition, there was a statistically significant inverse association between the $6 \mathrm{MWD}$ and the category of $\mathrm{SpO}_{2}$ change $(p=0.033)$. On post-hoc comparison, the 6MWD tended to be shorter in the group whose $\mathrm{SpO}_{2}$ decreased by at least $\%(353.98 \pm 138.27 \mathrm{~m})$ compared to the groups whose $\mathrm{SpO}_{2}$ were either unchanged $(392.99 \pm 119.17 \mathrm{~m}, p=0.05)$ or increased $(397.88 \pm 147.42 \mathrm{~m}, p=0.097)$, respectively. There were no statistically significant differences in Borg dyspnea scores, Fatigue scores, or pulse rates either at the start or end of the test among the three categories of $\mathrm{SpO}_{2}$ change.

Table 2. The 6-minute walk test measurements based on the change in $\mathrm{SpO}_{2}$ category.

\begin{tabular}{|c|c|c|c|c|}
\hline \multirow[b]{2}{*}{ 6MWT Variable } & \multicolumn{3}{|c|}{$\begin{array}{c}\text { Change in } \mathrm{SpO}_{2} \\
\left(\Delta=\mathrm{SpO}_{2} \text { at End of Study-SpO } \mathrm{Sp}_{2} \text { at Baseline }\right)\end{array}$} & \multirow[b]{2}{*}{$p$-Value } \\
\hline & $\begin{array}{c}\text { Increased } \\
(\Delta \geq+1) \\
N=60(19 \%)\end{array}$ & $\begin{array}{c}\text { Unchanged } \\
(-2 \leq \Delta \leq 0 \%) \\
N=146(46 \%)\end{array}$ & $\begin{array}{c}\text { Decreased } \\
(\Delta \leq-3 \%) \\
N=113(35 \%)\end{array}$ & \\
\hline \multicolumn{5}{|l|}{$\mathrm{SpO}_{2}, \%$} \\
\hline Start of test & $96.57 \pm 2.04$ & $97.99 \pm 1.89$ & $97.20 \pm 2.43$ & $<0.001^{1}$ \\
\hline End of test & $98.45 \pm 1.63$ & $97.10 \pm 2.10$ & $90.42 \pm 5.11$ & $<0.001^{1}$ \\
\hline Change & +1.88 & -0.89 & -6.78 & $<0.001^{2}$ \\
\hline \multicolumn{5}{|l|}{ Borg Dyspnea } \\
\hline Start of test & $1.52 \pm 1.64$ & $1.20 \pm 1.38$ & $1.00 \pm 1.34$ & 0.076 \\
\hline End of test & $3.51 \pm 1.93$ & $3.16 \pm 2.23$ & $3.86 \pm 6.97$ & 0.465 \\
\hline Change & +1.99 & +1.96 & +2.86 & 0.611 \\
\hline \multicolumn{5}{|l|}{ Borg Fatigue } \\
\hline Start of test & $1.43 \pm 1.90$ & $1.48 \pm 1.78$ & $1.28 \pm 1.65$ & 0.660 \\
\hline End of test & $3.51 \pm 3.07$ & $3.59 \pm 2.69$ & $2.82 \pm 2.31$ & 0.054 \\
\hline Change & +2.08 & +2.11 & +1.54 & 0.132 \\
\hline \multicolumn{5}{|l|}{ Pulse rate, $1 / \mathrm{min}$} \\
\hline Start of test & $79.13 \pm 15.26$ & $79.31 \pm 15.96$ & $80.73 \pm 14.53$ & 0.714 \\
\hline End of test & $103.88 \pm 24.07$ & $105.66 \pm 20.71$ & $113.77 \pm 78.72$ & 0.331 \\
\hline Change & +24.75 & +26.35 & +33.04 & 0.312 \\
\hline 6-minute walk distance, $\mathrm{m}$ & $397.88 \pm 147.42$ & $392.99 \pm 119.17$ & $353.98 \pm 138.27$ & $0.033^{1}$ \\
\hline
\end{tabular}


3.4. Demographic, and BMI Characteristics of $\geq 4 \%$ Oxygen Desaturators vs. Nondesaturators during the $6 \mathrm{MWT}$

After categorizing participants based on the presence of the occurrence of a $\geq 4 \%$ drop in $\mathrm{SpO}_{2}$, 95 of 319 subjects $(30 \%)$ were classified as $\geq 4 \%$ Desaturators while $224(70 \%)$ as Nondesaturators (Table 3). Age, spirometric lung volumes, and DLCO were statistically significantly associated with a drop of $\geq 4 \%$ in $\mathrm{SpO}_{2}$. The $\geq 4 \%$ Desaturators were statistically significantly older (57.96 \pm 13.20 vs. $52.92 \pm 14.11$ years), were more likely to have obstruction $\left(\mathrm{FEV}_{1}<70 \%\right)$, and had lower FVC, $\mathrm{FEV}_{1}, \mathrm{FEV}_{1} / \mathrm{FVC}$ ratio, and DLCO $(p<0.05)$ Sex, race, the prevalence of restriction or combined obstruction-restriction, RV, TLC, and airway resistance were not significantly different between $\geq 4 \%$ Desaturators and Nondesaturators.

Table 3. Demographic, clinical, and pulmonary function variables in $\geq 4 \%$ oxygen Desaturators vs. Nondesaturators during the 6-minute walk Test.

\begin{tabular}{|c|c|c|c|}
\hline Variable & $\begin{array}{c}\text { Nondesaturators } \\
\left(\Delta \mathrm{SpO}_{2}>-3 \%\right) \\
N=224(70 \%)\end{array}$ & $\begin{array}{c}\text { Desaturators } \\
\left(\Delta \mathrm{SpO}_{2} \leq-4 \%\right) \\
N=95(30 \%)\end{array}$ & $p$-Value \\
\hline Age, years & $52.92 \pm 14.11$ & $57.96 \pm 13.20$ & 0.003 \\
\hline \multicolumn{4}{|l|}{ Sex, no. $(\%)$} \\
\hline Male & $82(68)$ & $38(32)$ & 0.697 \\
\hline Female & $142(72)$ & $57(28)$ & \\
\hline \multicolumn{4}{|l|}{ Race, no. (\%) } \\
\hline White & $53(29)$ & $130(71)$ & \multirow{5}{*}{0.364} \\
\hline Black & $41(32)$ & $88(68)$ & \\
\hline Hispanic & $1(100)$ & $0(0)$ & \\
\hline Asian & $1(100)$ & $0(0)$ & \\
\hline Other & $0(0)$ & $1(100)$ & \\
\hline $\operatorname{BMI}\left(\mathrm{kg} / \mathrm{m}^{2}\right)$ & $29.42 \pm 8.10$ & $30.14 \pm 8.19$ & 0.472 \\
\hline Obstruction $\left(\mathrm{FEV}_{1} / \mathrm{FVC}<70 \%\right)$, no. $(\%)$ & $39(40)$ & $59(60)$ & 0.01 \\
\hline Restriction $($ TLC $<80 \%)$, no. $(\%)$ & $33(34.4)$ & $63(65.6)$ & 0.238 \\
\hline $\begin{array}{c}\text { Combined obstruction and restriction, } \\
\text { no. }(\%)\end{array}$ & $3(3.2)$ & $2(1.8)$ & 0.444 \\
\hline FVC, L & $2.88 \pm 0.9$ & $92.43 \pm 1.05$ & 0.001 \\
\hline FVC, \%predicted & $78.05 \pm 16.51$ & $68.55 \pm 24.84$ & 0.002 \\
\hline $\mathrm{FEV}_{1}, \mathrm{~L}$ & $2.10 \pm 0.82$ & $1.59 \pm 0.74$ & $<0.001$ \\
\hline $\mathrm{FEV}_{1}, \%$ predicted & $72.72 \pm 21.55$ & $57.64 \pm 21.85$ & $<0.001$ \\
\hline $\mathrm{FEV}_{1} / \mathrm{FVC}$ ratio & $73.14 \pm 15.80$ & $67.39 \pm 21.38$ & 0.027 \\
\hline TLC, L & $4.94 \pm 1.45$ & $4.55 \pm 1.55$ & 0.05 \\
\hline TLC, \% predicted & $90.89 \pm 20.44$ & $85.08 \pm 28.09$ & 0.094 \\
\hline $\mathrm{RV}, \mathrm{L}$ & $2.10 \pm 1.00$ & $2.16 \pm 1.10$ & 0.636 \\
\hline $\mathrm{RV}$, \%predicted & $114.85 \pm 50.58$ & $114.89 \pm 58.69$ & 0.996 \\
\hline $\mathrm{DLCO}, \mathrm{mL} / \mathrm{min} / \mathrm{mmHg}$ & $15.28 \pm 5.92$ & $9.77 \pm 4.35$ & $<0.001$ \\
\hline DLCO, \%predicted & $68.54 \pm 24.81$ & $42.51 \pm 19.25$ & $<0.001$ \\
\hline Airway resistance, $\mathrm{cmH}_{2} \mathrm{O} / \mathrm{L} / \mathrm{sec}$ & $1.95 \pm 1.33$ & $2.20 \pm 1.33$ & 0.144 \\
\hline
\end{tabular}

3.5. The 6-Minute Walk Test Results of $\geq 4 \%$ Oxygen Desaturators vs. Nondesaturators during the $6 M W T$

The baseline $\mathrm{SpO}_{2}$, Borg Dyspnea Scale score, Fatigue score and pulse rate were similar between $\geq 4 \%$ Desaturators and Nondesaturators (Table 4 ). At the end of the $6 \mathrm{MWT}$, the $\geq 4 \%$ Desaturators were statistically significantly more hypoxemic than the Nondesaturators $\left(\mathrm{SpO}_{2}: 89.67 \pm 5.15\right.$ vs. $97.24 \pm 2.26 \%, p<0.001)$. The $\geq 4 \%$ Desaturators also had a statistically shorter $6 \mathrm{MWD}(352.67 \pm 138.19$ vs. $391.69 \pm 128.83 \mathrm{~m}, p=0.017)$. There were no statistically significant differences in the changes in Borg Dyspnea and Fatigue Scale scores and pulse rate from the start to the end of the 6MWT between the $\geq 4 \%$ Desaturators and Nondesaturators. 
Table 4. The 6-minute walk test measurements in $\geq 4 \%$ oxygen Desaturators vs. Nondesaturators.

\begin{tabular}{|c|c|c|c|}
\hline 6MWT Variables & $\begin{array}{c}\text { Nondesaturators } \\
\left(\Delta \mathrm{SpO}_{2}>-3 \%\right) \\
N=224(70 \%)\end{array}$ & $\begin{array}{c}\text { Desaturators } \\
\left(\begin{array}{c}\left.\Delta \mathrm{SpO}_{2} \leq-4 \%\right) \\
N=95(30 \%)\end{array}\right.\end{array}$ & $p$-Value \\
\hline \multicolumn{4}{|l|}{$\mathrm{SpO}_{2}, \%$} \\
\hline Start of test & $97.56 \pm 2.07$ & $97.18 \pm 2.43$ & $0.157^{1}$ \\
\hline End of test & $97.24 \pm 2.26$ & $89.67 \pm 5.15$ & $<0.001^{1}$ \\
\hline Change & -0.32 & -7.51 & $<0.001^{2}$ \\
\hline \multicolumn{4}{|l|}{ Borg Dyspnea } \\
\hline Start of test & $1.26 \pm 1.48$ & $1.02 \pm 1.29$ & 0.163 \\
\hline End of test & $3.26 \pm 2.13$ & $3.97 \pm 7.55$ & 0.196 \\
\hline Change & +2.00 & +2.95 & 0.465 \\
\hline \multicolumn{4}{|l|}{ Borg Fatigue } \\
\hline Start of test & $1.46 \pm 1.83$ & $1.26 \pm 1.57$ & 0.354 \\
\hline End of test & $3.52 \pm 2.77$ & $2.77 \pm 2.28$ & 0.012 \\
\hline Change & +2.06 & +1.51 & 0.053 \\
\hline \multicolumn{4}{|l|}{ Pulse rate, $1 / \mathrm{min}$} \\
\hline Start of test & $79.29 \pm 15.30$ & $80.93 \pm 15.34$ & 0.383 \\
\hline End of test & $108.96 \pm 57.87$ & $106.33 \pm 21.38$ & 0.669 \\
\hline Change & +29.67 & +25.40 & 0.848 \\
\hline inute walk distance, $\mathrm{m}$ & $391.69 \pm 128.83$ & $352.67 \pm 138.19$ & $0.017^{1}$ \\
\hline
\end{tabular}

${ }^{1} p$-value from comparison based on categories of the change in $\mathrm{SpO}_{2}$ by ANOVA. ${ }^{2} p$-value from comparison based on categories of the change in $\mathrm{SpO}_{2}$ by Repeated Measures ANOVA.

\subsection{Regression Models to Predict Changes in $\mathrm{SpO}_{2}$ and $a \geq 4 \%$ Oxygen Desaturation during the $6 \mathrm{MWT}$}

A multivariable linear regression model was fit to determine whether the magnitude of the change in $\mathrm{SpO}_{2}$ (as a continuous variable) during the $6 \mathrm{MWT}$ was associated with the statistically significant independent variables (i.e., age, $\mathrm{FVC} \mathrm{FEV}_{1}$, and DLCO) in the unadjusted analysis (Table 5). Although the FEV1/FVC ratio and the presence of obstruction based on the same ratio were found to be statistically significant in the bivariate analysis, we excluded them in the model in order to avoid multicollinearity. This linear regression model revealed that after adjusting for age, $\mathrm{FEV}_{1}$, and FVC, the DLCO was the only statistically significant predictor of the change in $\mathrm{SpO}_{2}$ during a 6MWT $(\beta=-0.306$ $\left.\pm 0.072, t=-4.271, p<0.001, R^{2}=0.147\right)$. Based on the $R^{2}$, this linear regression model using age, FVC, $\mathrm{FEV}_{1}$, and DLCO as covariates accounts for $15 \%$ of the variance in the change in $\mathrm{SpO}_{2}$ during a $6 \mathrm{MWT}$.

Table 5. Linear regression model predicting the change in $\mathrm{SpO}_{2}$ from start to end of the 6-minute walk test.

\begin{tabular}{ccc}
\hline Variable & Parameter Estimate $(\boldsymbol{\beta}) \pm$ Standard Error & $\boldsymbol{p}$-Value \\
\hline (Constant) & $4.886 \pm 1.783$ & 0.007 \\
Age, years & $0.002 \pm 0.024$ & 0.933 \\
FVC, L & $0.254 \pm 0.79$ & 0.748 \\
$\mathrm{FEV}_{1}, \mathrm{~L}$ & $0.197 \pm 1.022$ & 0.847 \\
$\mathrm{DLCO}, \mathrm{mL} / \mathrm{min} / \mathrm{mmHg}$ & $-0.291 \pm 0.071$ & $<0.001$ \\
\hline
\end{tabular}

A binary logistic regression model was initially fitted to determine whether the age, FVC, $\mathrm{FEV}_{1}$, and DLCO predicted the occurrence of $\mathrm{O}_{2}$ desaturation of $\geq 3 \%$ during the 6MWT (Table 6). None of the independent variables (i.e., age, FVC, FEV1, and DLCO) was found to be a statistically significant predictor of a $\geq 3 \%$ drop in $\mathrm{SpO}_{2}$ during a $6 \mathrm{MWT}$. On the other hand, a second logistic regression model identified the DLCO as the only independent predictor of a $\geq 4 \%$ drop in $\mathrm{SpO}_{2}$ drop during a 6MWT $\left(\beta=-0.289 \pm 0.068\right.$, Wald $\chi^{2}=17.887, p<0.001$, Nagelkerke $\left.R^{2}=0.276\right)$ (Table 7). Based on the 
Naegelkerke $R^{2}$, this logistic regression model using age, FVC, $\mathrm{FEV}_{1}$, and DLCO as covariates accounts for $28 \%$ of the variance of the outcome, i.e., a $\geq 4 \%$ drop in $\mathrm{SpO}_{2}$ during the $6 \mathrm{MWT}$.

Table 6. Logistic regression predicting an oxygen desaturation $\geq 3 \%$ during a 6-minute walk test.

\begin{tabular}{cccc}
\hline Variable & Odds Ratio & 95\% Confidence Interval & $\boldsymbol{p}$-Value \\
\hline Age, years & 0.951 & $0.892,1.014$ & 0.125 \\
FVC, L & 0.883 & $0.070,11.203$ & 0.923 \\
FEV $_{1}, \mathrm{~L}$ & 2.816 & $0.081,98.292$ & 0.568 \\
DLCO, $\mathrm{mL} / \mathrm{min} / \mathrm{mmHg}$ & 0.909 & $0.742,1.115$ & 0.360 \\
\hline
\end{tabular}

Table 7. Logistic regression predicting an oxygen desaturation $\geq 4 \%$ during a 6 -minute walk test.

\begin{tabular}{cccc}
\hline Variable & Odds Ratio & 95\% Confidence Interval & $\boldsymbol{p}$-Value \\
\hline Age, years & 1.003 & $0.973,1.034$ & 0.859 \\
FVC, L & 0.581 & $0.174,1.933$ & 0.376 \\
FEV $_{1}, \mathrm{~L}$ & 3.574 & $0.751,17.014$ & 0.110 \\
DLCO, $\mathrm{mL} / \mathrm{min} / \mathrm{mmHg}$ & 0.749 & $0.655,0.856$ & $<0.001$ \\
\hline
\end{tabular}

\subsection{Receiver Operating Characteristics of DLCO \% for Detection of $\geq 4 \%$ Oxygen Desaturation during} the $6 M W T$

A receiver operating characteristic (ROC) curve was plotted to determine the performance of the DLCO $\%$ of predicted as a diagnostic test for detecting a $\geq 4 \% \mathrm{O}_{2}$ desaturation during a $6 \mathrm{MWT}$ (Figure 1). The analysis of the ROC curve revealed a statistically significant area under the curve of $0.788 \pm 0.039(p<0.001)$, which means that the DLCO $\%$ is a good diagnostic test to discriminate $\mathrm{O}_{2}$ desaturators from non-desaturators. A diagnostic DLCO $\%$ cut-off of $45 \%$ has a sensitivity of $81.8 \%$ and a specificity of $39.5 \%$.

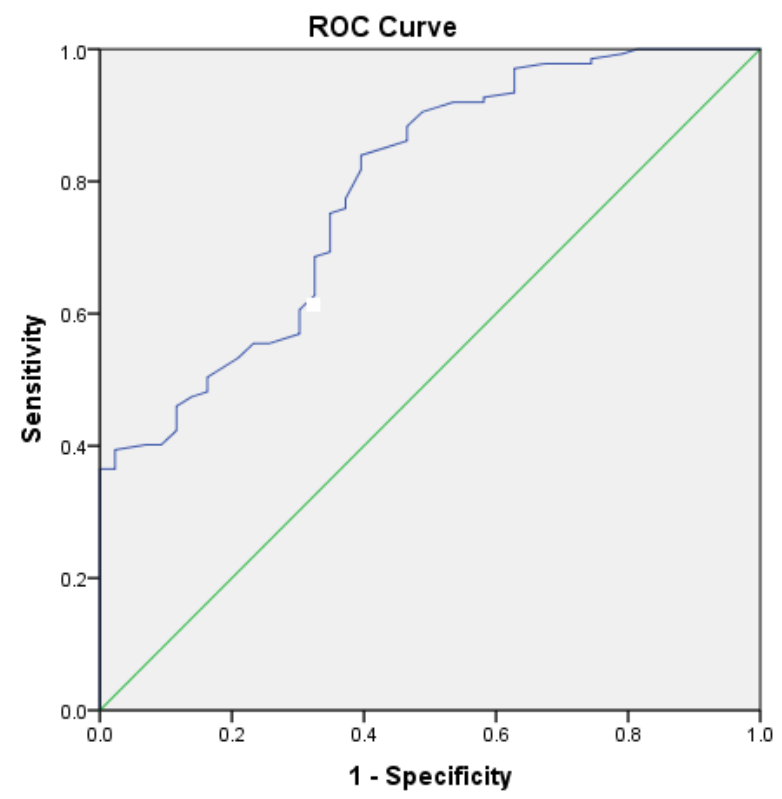

Figure 1. A receiver operating characteristic curve illustrating the performance of the diffusion capacity for carbon monoxide (DLCO \%) of predicted as a diagnostic test for identifying patients who develop $\geq 4 \%$ oxygen desaturation during a 6 -minute walk test. The area under the curve was $0.788 \pm 0.039$ $(p<0.001)$. 


\section{Discussion}

This retrospective study focused on EID during a 6MWT presents two main findings: (1) the prevalence of $a \geq 3 \%$ oxygen desaturation via pulse oximetry during a $6 \mathrm{MWT}$ in a clinical population of patients with suspected cardiopulmonary disease is 35\%; and (2) although age, spirometry lung volumes, and DLCO have a statistically significant unadjusted inverse association with the change in $\mathrm{SpO}_{2}$ during a $6 \mathrm{MWT}$, the DLCO is the only significant independent predictor of both the magnitude of the change in $\mathrm{SpO}_{2}$ and the occurrence of $\mathrm{O}_{2}$ desaturation of at least $4 \%$, respectively, during the test.

Our study found that approximately one out of three clinic patients who underwent 6MWT for suspected cardiopulmonary disease at our academic medical center developed EID of at least 3\% during the test. Currently, based on our review of the literature, there are no population-based studies to define the reference ranges based on age, sex, anthropometric characteristics (height, weight, BMI) for changes in $\mathrm{SpO}_{2}$ during a $6 \mathrm{MWT}$. We believe that our estimated prevalence may only apply to patients with moderate-to-severe pulmonary disease based on the overall mean $\mathrm{FEV}_{1} \%$ predicted $(68.56 \pm 22.52 \%)$ of the patients included in our analysis. Our study's estimated $35 \%$ prevalence of $\geq 3 \%$ $\mathrm{O}_{2}$ desaturation corroborates the common occurrence of EID during a 6MWT in other studies: 53\% prevalence of $\geq 10 \%$ desaturation in pulmonary hypertensive patients in the Paciocco study [19] and $47 \%$ prevalence of a $4 \%$ desaturation in patients with chronic lung disease in the Jenkins study [20]. The lower prevalence of $\mathrm{O}_{2}$ desaturation in our cohort with various cardiopulmonary disorders may be due to the inclusion of patients with less severe pulmonary function derangement.

Our unadjusted statistical analysis found a statistically significant inverse relationship between age, spirometry lung function (FVC, $\mathrm{FEV}_{1}$, and $\mathrm{FEV}_{1} / \mathrm{FVC}$ ratio), and $\mathrm{DLCO}$ and the category of $\mathrm{SpO}_{2}$ change (decreased, unchanged, increased). In other words, older age and worsening spirometry lung function and diffusion capacity are significantly associated with $\mathrm{a} \geq 3 \%$ drop in $\mathrm{O}_{2}$ desaturation during a 6MWT. Our study findings corroborate those of Wilsher et al.'s, which found a strong correlation between $\mathrm{O}_{2}$ desaturation and both the $\mathrm{FEV}_{1}(r=0.55, p=0.01)$ and the FVC $(r=0.59, p=0.01)$ in 30 patients with scleroderma lung disease who underwent 6MWT [17].

On the other hand, our multivariable linear and logistic regression analyses revealed that, after adjusting for age and spirometry lung volumes, the DLCO was the only significant independent predictor of both the magnitude of the change in $\mathrm{SpO}_{2}$ and the occurrence of $\geq 4 \%$ desaturation, respectively, during the test. In fact, our adjusted logistic regression model incorporating DLCO as predictor and age, $\mathrm{FEV}_{1}$, and FVC as covariates accounted for up to $28 \%$ of the variance in the outcome, i.e., occurrence of $\geq 4 \%$ desaturation during a $6 \mathrm{MWT}$. Our ROC curve analysis also revealed that the DLCO $\%$ of predicted was a statistically significant test variable to discriminate $\geq 4 \% \mathrm{O}_{2}$ Desaturators from Nondesaturators. Based on the ROC curve, we propose a diagnostic DLCO cut-off of $45 \%$ of predicted, which corresponds to a sensitivity of $81.8 \%$ and a specificity of $39.5 \%$.

Our study finding on the strong inverse association between DLCO and the $\mathrm{O}_{2}$ desaturation was also corroborated by a number of published studies. Chetta et al., who reported that $\mathrm{O}_{2}$ desaturation during a $6 \mathrm{MWT}$ was predicted by DLCO, particularly with a cut-off $57 \%$ of predicted [23]. Hadeli et al. investigated the risk of $\mathrm{O}_{2}$ desaturation during a submaximal step exercise test in 8000 patients of various respiratory diseases. Not only did they confirm that that the risk of $\mathrm{O}_{2}$ desaturation was very high in patients with a low DLCO, but that a DLCO diagnostic cut-off point of $<62 \%$ predicted resulted in a 75\% sensitivity and specificity for EID [24]. In a retrospective study of 97 patients, the DLCO had a slightly better ability to predict $\mathrm{O}_{2}$ desaturation than the DLCO/VA, with a cut-off of normal being $55 \%$ predicted [25].

The early detection of EID is important in the management of patients with suspected cardiopulmonary disease since $\mathrm{O}_{2}$ supplementation has been demonstrated to ameliorate dyspnea and fatigue as well as enhance exercise capacity in patients with exercise-induced hypoxemia even in the absence of resting hypoxemia [26]. The early detection of a reduced DLCO on a PFT can prompt the physician to order a 6MWT to diagnose EID and subsequently prescribe ambulatory $\mathrm{O}_{2}$ therapy for relief of symptoms and enhancement of exercise capacity. Randomized, controlled 
trials with longitudinal follow up are still necessary to determine whether ambulatory $\mathrm{O}_{2}$ therapy for exercise-induced hypoxemia, in the absence of resting hypoxemia, is beneficial in improving survival and other long-term health outcomes in various cardiopulmonary diseases.

The strengths of our study include the large sample size, the standardized PFT and 6MWT protocols, and the statistical adjustments employed to identify significant independent predictor/s of $\mathrm{O}_{2}$ desaturation during a 6MWT. On the other hand, the limitations of our study are the following: (1) The retrospective study design prevented us from ascertaining the specific cardiopulmonary disease diagnoses for each of the participants, given the limited clinical information available in the PFT laboratory records for our review. Although we were able to identify patients with obstruction, restriction, or combined abnormality based on the PFT, we were unable to compare the propensity for EID during the 6MWT among specific disease etiologies. (2) Selection bias is likely present in our study since we retrospectively selected a convenience sample of clinical patients who underwent 6MWT for suspected cardiopulmonary disease. In order to limit this selection bias, we included all patients who underwent 6MWT within the designated study period and adjusted our final statistical model based on significant confounders (age and spirometric lung function). (3) Since $\mathrm{O}_{2}$ desaturation was only measured at the start and at end of the $6 \mathrm{MWT}$, some patients who developed hypoxemia in the middle of the test have been misclassified as "Nondesaturators". Measuring $\mathrm{SpO}_{2}$ continuously throughout the 6MWT was prohibited in ATS 2002 guidelines which became a formal recommendation in the update of ERS/ATS 2014 measurement properties of field walking tests in chronic respiratory disease $[4,18]$. Fiore et al. showed that the $\mathrm{SpO}_{2}$ at the end of the test and the nadir $\mathrm{SpO}_{2}$ were generally similar during the 6MWT in 86 subjects with chronic lung disease except in those subjects who rested during the test. Fiore's group thus concluded that consideration should be given to the constant monitoring of $\mathrm{SpO}_{2}$ during the 6MWT [27]. Our 6MWT protocol did not include continuous $\mathrm{SpO}_{2}$ monitoring during the $6 \mathrm{MWT}$, which might have resulted in failing to detect abnormally low nadir $\mathrm{SpO}_{2}$ in some patients, leading to the underestimation of the prevalence of EID in our study. A prospective study of both community based and clinical populations (with ascertainment of specific cardiopulmonary disease etiology) using continuous $\mathrm{SpO}_{2}$ monitoring during a $6 \mathrm{MWT}$ will help clarify both the normative ranges and pathologic values of $\mathrm{SpO}_{2}$ changes for this test.

In conclusion, the prevalence of $\mathrm{a} \geq 3 \%$ oxygen desaturation via pulse oximetry during a $6 \mathrm{MWT}$ in our clinical population of patients with suspected cardiopulmonary disease is $35 \%$. Although age, spirometry lung volumes, and DLCO all had statistically significant unadjusted inverse associations with the change in $\mathrm{SpO}_{2}$ during a $6 \mathrm{MWT}$, the DLCO is the only significant independent predictor of both the magnitude of the change in $\mathrm{SpO}_{2}$ and the occurrence of $\mathrm{O}_{2}$ desaturation of at least $4 \%$, respectively, during the test.

Author Contributions: Conceptualization, R.G., G.L.R. and J.R.D.E.; methodology, J.R.D.E.; software, J.R.D.E.; validation, J.R.D.E.; formal analysis, R.G., G.L.R. and J.R.D.E.; investigation, R.G., G.L.R. and J.R.D.E.; resources, G.L.R. and J.R.D.E.; data curation, R.G., G.L.R. and J.R.D.E.; writing-original draft preparation, R.G.; writing - review and editing, R.G. and J.R.D.E.; supervision, R.G. and J.R.D.E.; project administration, R.G. All authors have read and agreed to the published version of the manuscript.

Funding: This research received no external funding.

Conflicts of Interest: The authors declare no conflict of interest.

\section{References}

1. Weisman, I.M.; Zeballos, R.J. An integrated approach to the interpretation of cardiopulmonary exercise testing. Clin. Chest Med. 1994, 15, 421-445. [PubMed]

2. Solway, S.; Brooks, D.; Lacasse, Y.; Thomas, S. A qualitative systematic overview of the measurement properties of functional walk tests used in the cardiorespiratory domain. CHEST J. 2001, 119, 256-270. [CrossRef] [PubMed] 
3. Guyatt, G.H.; Thompson, P.J.; Berman, L.B.; Sullivan, M.J.; Townsend, M.; Jones, N.L.; Pugsley, S.O. How should we measure function in patients with chronic heart and lung disease? J. Chronic Dis. 1985, 38, 517-524. [CrossRef]

4. Crapo, R.O. ATS statement: Guidelines for the six-minute walk test. Am. J. Respir. Crit. Care Med. 2002, 166, 111-117.

5. Andrianopoulos, V.; Wouters, E.F.; Pinto-Plata, V.M.; Vanfleteren, L.E.; Bakke, P.S.; Franssen, F.M.; Agusti, A.; MacNee, W.; Rennard, S.I.; Singer, R.T.; et al. Prognostic value of variables derived from the six-minute walk test in patients with COPD: Results from the ECLIPSE study. Respir. Med. 2015, 109, 1138-1146. [CrossRef]

6. Dajczman, E.; Wardini, R.; Kasymjanova, G.; Préfontaine, D.; Baltzan, M.A.; Wolkove, N. Six-minute walk distance is a predictor of survival in patients with chronic obstructive pulmonary disease undergoing pulmonary rehabilitation. Can. Respir. J. 2015, 22, 225-229. [CrossRef]

7. Casanova, C.; Cote, C.; Marin, J.M.; Pinto-Plata, V.; de Torres, J.P.; Aguirre-Jaíme, A.; Vassaux, C.; Celli, B.R. Distance and oxygen desaturation during the 6-min walk test as predictors of long-term mortality in patients with COPD. CHEST J. 2008, 134, 746-752. [CrossRef]

8. Singh, S.J.; Puhan, M.A.; Andrianopoulos, V.; Hernandes, N.A.; Mitchell, K.E.; Hill, C.J.; Lee, A.L.; Camillo, C.A.; Troosters, T.; Spruit, M.A.; et al. An official systematic review of the European Respiratory Society/American Thoracic Society: Measurement properties of field walking tests in chronic respiratory disease. Eur. Respir. J. 2014, 44, 1447-1478. [CrossRef]

9. Chen, H.; Liang, B.M.; Tang, Y.J.; Wang, K.; Yi, Q.; Ou, X.M.; Feng, Y.L. Relationship between 6-minute walk test and pulmonary function test in stable chronic obstructive pulmonary disease with different severities. Chin. Med. J. 2012, 125, 3053-3058.

10. Garin, M.C.; Highland, K.B.; Silver, R.M.; Strange, C. Limitations to the 6-minute walk test in interstitial lung disease and pulmonary hypertension in scleroderma. J. Rheumatol. 2009, 36, 330-336. [CrossRef]

11. Deuschle, K.; Weinert, K.; Becker, M.O.; Backhaus, M.; Huscher, D.; Riemekasten, G. Six-minute walk distance as a marker for disability and complaints in patients with systemic sclerosis. Clin. Exp. Rheumatol. Incl Suppl. 2011, 29, S53.

12. Nishiyama, O.; Yamazaki, R.; Sano, H.; Iwanaga, T.; Higashimoto, Y.; Kume, H.; Tohda, Y. Pulmonary Hemodynamics and Six-Minute Walk Test Outcomes in Patients with Interstitial Lung Disease. Can. Respir. J. 2016. [CrossRef] [PubMed]

13. Poulain, M.; Durand, F.; Palomba, B.; Desplan, J.; Varray, A. 6-minute walk testing is more sensitive than maximal incremental cycle testing for detecting oxygen desaturation in patients with COPD. CHEST J. 2003, 123, 1401-1407. [CrossRef] [PubMed]

14. Guyatt, G.H.; Townsend, M.; Keller, J.; Slnger, J.; Nogradi, S. Measuring functional status in chronic lung disease: Conclusions from a randomized control trial. Respir. Med. 1991, 85, 17-21. [CrossRef]

15. Barthelemy, J.C.; Geyssant, A.; Riffat, J.; Antoniadis, A.; Berruyer, J.; LaCour, J.R. Accuracy of pulse oximetry during moderate exercise: A comparative study. Scand. J. Clin. Lab. Investig. 1990, 50, 533-539. [CrossRef]

16. Ziegler, B.; Rovedder, P.M.; Oliveira, C.L.; e Silva, F.D.; Dalcin, P.D. Repeatability of the 6-minute walk test in adolescents and adults with cystic fibrosis. Respir. Care 2010, 55, 1020-1025.

17. Wilsher, M.; Good, N.; Hopkins, R.; Young, P.; Milne, D.; Gibson, A.; Suppiah, R.; Ly, J.; Doughty, R.; Dalbeth, N. The six-minute walk test using forehead oximetry is reliable in the assessment of scleroderma lung disease. Respirology 2012, 17, 647-652. [CrossRef]

18. Holland, A.E.; Spruit, M.A.; Troosters, T.; Puhan, M.A.; Pepin, V.; Saey, D.; McCormack, M.C.; Carlin, B.W.; Sciurba, F.C.; Pitta, F.; et al. An official European Respiratory Society/American Thoracic Society technical standard: Field walking tests in chronic respiratory disease. Eur. Respir. J. 2014, 44, 1428-1446. [CrossRef]

19. Paciocco, G.; Martinez, F.J.; Bossone, E.; Pielsticker, E.; Gillespie, B.; Rubenfire, M. Oxygen desaturation on the six-minute walk test and mortality in untreated primary pulmonary hypertension. Eur. Respir. J. 2001, 17, 647-652. [CrossRef]

20. Jenkins, S.; Čečins, N. Six-minute walk test: Observed adverse events and oxygen desaturation in a large cohort of patients with chronic lung disease. Intern. Med. J. 2011, 41, 416-422. [CrossRef]

21. Chetta, A.; Pisi, G.; Zanini, A.; Foresi, A.; Grzincich, G.L.; Aiello, M.; Battistini, A.; Olivieri, D. Six-minute walking test in cystic fibrosis adults with mild to moderate lung disease: Comparison to healthy subjects. Respir. Med. 2001, 95, 986-991. [CrossRef] [PubMed] 
22. Nitzan, M.; Romem, A.; Koppel, R. Pulse oximetry: Fundamentals and technology update. Med. Devices 2014, 7, 231-239. [CrossRef] [PubMed]

23. Chetta, A.; Aiello, M.; Foresi, A.; Marangio, E.; D’Ippolito, R.; Castagnaro, A.; Olivieri, D. Relationship between outcome measures of six-minute walk test and baseline lung function in patients with interstitial lung disease. Sarcoidosis Vasc. Diffus. lung Dis. Off. J. WASOG 2001, 18, 170-175.

24. Hadeli, K.O.; Siegel, E.M.; Sherrill, D.L.; Beck, K.C.; Enright, P.L. Predictors of oxygen desaturation during submaximal exercise in 8000 patients. CHEST J. 2001, 120, 88-92. [CrossRef]

25. Kaminsky, D.A.; Whitman, T.; Callas, P.W. DLCO versus DLCO/VA as predictors of pulmonary gas exchange. Respir. Med. 2007, 101, 989-994. [CrossRef]

26. Ahmadi, Z.; Sundh, J.; Bornefalk-Hermansson, A.; Ekström, M. Long-Term Oxygen Therapy 24 vs 15 h/day and Mortality in Chronic Obstructive Pulmonary Disease. PLoS ONE 2016, 11, e0163293. [CrossRef]

27. Fiore, C.B.; Lee, A.L.; McDonald, C.F.; Hill, C.J.; Holland, A.E. Should oxyhaemoglobin saturation be monitored continuously during the 6-minute walk test? Chronic Respir. Dis. 2011, 8, 181-184. [CrossRef]

(C) 2020 by the authors. Licensee MDPI, Basel, Switzerland. This article is an open access article distributed under the terms and conditions of the Creative Commons Attribution (CC BY) license (http://creativecommons.org/licenses/by/4.0/). 